\title{
Editorial
}

\section{Simposio Abdomen Agudo}

\author{
Acute Abdomen symposium
}

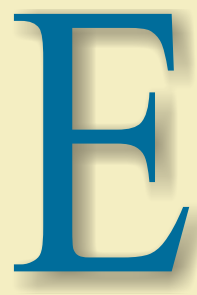

1 abdomen agudo es un síndrome muy frecuente en la práctica médica, cuyo principal síntoma es el dolor abdominal, el que puede responder a una enfermedad no específica. El 14-40\% de abdómenes agudos son médicos, de estricto manejo conservador aun cuando el dolor abdominal puede tener características de abdomen agudo quirúrgico que señalaremos más adelante. Usualmente corresponde al médico general o emergenciólogo el que evalúa inicialmente al paciente y el que define la conducta médica a seguir, en caso se trate de dolor abdominal por enfermedad inespecífica o convocando al cirujano si sospecha que podría tratarse de un problema quirúrgico.

El abdomen agudo quirúrgico puede presentarse en forma brusca, insidiosa, progresivamente más severo, intermitente o continuo, con características particulares de punzante, cólico, quemante y otros. Paralelamente puede ir acompañado de náuseas y vómitos, diarreas, fiebre, estreñimiento, ictericia, palidez. hipotensión y/o shock, etc.

Muy importante es la historia clínica que nos revela las características clínicas del paciente, conocer sus antecedentes médicos o enfermedades concomitantes, uso de fármacos, alergias, etc.

En el examen clínico la localización del dolor, local o referido, los signos de contractura abdominal, y el clásico signo del rebote, así como la presencia o no de ruidos abdominales con algunas características de timpánico o ausentes, pueden orientarnos al órgano responsable del proceso.
Si el médico evaluador considera que pudiera tratarse de un abdomen agudo quirúrgico debe llamar en consulta al cirujano para que juntos completen la evaluación. En líneas generales los cuadros de dolor abdominal inespecíficos son producidos por enfermedades inflamatorias del intestino que no requieren manejo quirúrgico $u$ otros procesos referidos (neumonía basal, enfermedades hematológicas, etc.). Por el contario los cuadros de necesidad quirúrgica por lo general deben ser operados en el menor tiempo posible En cualquier caso, intervenir quirúrgicamente cuadros de naturaleza médica o dejar de operar cuadros de necesidad quirúrgica con llevan alto riesgo de morbimortalidad. De allí que siempre el abdomen agudo es un reto para médicos generales y cirujanos. El error diagnóstico tiene consecuencias lamentables.

En los últimos 50 años se ha podido mejorar y afinar los diagnósticos pre operatorios con el progreso que ofrece la tecnología. Hasta finales del siglo pasado el diagnóstico clínico era exclusivo para definir la conducta terapéutica. Con la aparición de la ultrasonografía primero y posterior tomografía axial computarizada se ha podido afinar el diagnóstico y la conducta terapéutica con menos errores diagnósticos.

La mortalidad general de las operaciones de emergencia alcanzan el 15\% (rango de $0.5 \%-80 \%$ a diferencia de las operaciones electivas que son alrededor del 3\% (rango de $0.5-5 \%)$. La mortalidad de los cuadros quirúrgicos de abdomen agudo dependen de varios factores, como la causa del proceso, la edad del paciente, el tiempo de enfermedad, 
enfermedades concomitantes, la experiencia del cirujano (un residente de primer año o un cirujano de experiencia), el anestesiólogo, las facilidades del centro médico, etc. Por eso si el proceso abdominal puede manejarse conservadoramente y programarlo diferida es mejor postergar a una operación electiva, siempre y cuando el riesgo de espera no sea mayor que el riesgo de intervenir en el primer momento. En los últimos tiempos la urgencia de intervenir en pleno proceso agudo ha disminuido en algunas patologías, aunque todavía son más frecuentes las que necesariamente deben operarse en el primer momento. En este sentido el desarrollo de la cirugía laparoscópica ha mejorado el pronóstico de los pacientes con abdomen agudo, por cuanto facilita el diagnóstico en casos muy complejos con una exploración laparoscópica que puede convertirse en terapéutica en el mismo momento si fuera necesario.

Es muy importante remarcar que si no es posible tomar decisiones en el primer examen clínico, la espera de los resultados de los exámenes auxiliares, nos permite reevaluar clínicamente en forma horaria al paciente mientras se inicia un proceso de hidratación endovenosa, y uso de drogas como antibióticos, corregir anticoagulación, manejo respiratorio, etc; preparando al paciente para un acto quirúrgico de emergencia recurriendo a los otros especialistas para apoyo en caso el paciente refiera tener enfermedades concoconcomitantes como diabetes, historia de insuficiencias cardíaca, renal o respiratoria, o ser de la tercera edad, etc. Igualmente es fundamental la evaluación por el anestesiólogo si es que se define el tratamiento quirúrgico.

Para este simposio hemos invitado a destacados cirujanos abdominales para tratar algunas de las patologías más frecuentes observadas en los servicios de emergencia.

AH Dr. Eduardo Barboza Besada, FACS, FRCS. Profesor Emérito Universidad Peruana Cayetano Heredia.

Citar como: Simposio Abdomen Agudo. Diagnóstico (Lima). 2020;59(4):171-172.

DOI: 10.33734/diagnostico.v59i4.250

Correspondencia: Eduardo Barboza Besada. Correo electrónico:eduardo.barboza@upch.pe 